\section{Emphysema, lung disease and retinoic acid}

To the editor - The recent article ${ }^{1}$ by Massaro \& Massaro concerning the abrogation of experimental pulmonary emphysema by retinoic acid (RA) leaves the impression that the use of this agent represents an entirely new treatment for lung disease. This is not the case. In 1979, this laboratory described the effects of RA in experimental pulmonary fibrosis ${ }^{2}$. It was hypothesized that RA might arrest the alveolar epithelial proliferation occurring in this disease process and thereby reduce lung damage. While no such effect was observed during the eight months that the animals (hamsters) were fed RA, there was nevertheless a sustained increase in alveolar macrophages between the months 4-8, suggesting that RA may stimulate these cells. It was speculated that RA might reduce the extent of lung injury with lower doses of the fibrosing agent (N-nitroso-N-methylurethane), but such studies were never undertaken.

We have also become concerned with the treatment of pulmonary emphysema, publishing work ${ }^{3}$ that demonstrates that intratracheal administration of hyaluronic acid ameliorates alveolar injury in the same elastase model used by the Massaros. This route of administration concentrates the hyaluronic acid in the lungs, allowing for the use of smaller doses, and may be equally effective with regard to RA. In view of the possible teratogenic effects of high doses of $\mathrm{RA}$, aerosolization of this agent may be the treatment of choice.

\section{JEROME CANTOR}

The Brooklyn Hospital Center

Department of Pathology

121 DeKalb Avenue

Brooklyn, NY 11201

Massaro \& Massaro reply - Dr. Cantor states that our article "leaves the impression that the use of this agent [retinoic acid] represents an entirely new treatment for lung disease." We have carefully reread our paper with that possibility in mind but have been unable to find anything (words or nuances) that should have led him to that conclusion. We are aware of studies in humans where retinol, a precursor of retinoic acid, has been used in the treatment of lung disease $^{4-6}$ but our work specifically addresses the use of retinoic acid to induce the formation of alveoli in an animal model of human emphysema. We would be eager to learn about any earlier work, published or unpublished, on the use of retinoids for this purpose.

The hypothesis that retinoic acid might arrest alveolar epithelial proliferation in experimental fibrosis ${ }^{2}$ is interesting but entirely unrelated to our work on alveolar regeneration in elastase-induced emphysema. Cantor's work ${ }^{7}$ showing that the intratracheal administration of hyaluronic acid ameliorates alveolar injury in rats treated with elastase is also interesting but also clearly unrelated to our work. He examines prevention of the induction of emphysema by elastase, whereas we look at the abrogation of key components of already established emphysema.

\section{Gloria D. Massaro \&}

DONALD MASSARO

Lung Biology Laboratory

Georgetown University School of Medicine

Washington, D.C. 20007

1. Massaro, G.D. \& Massaro, D. Retinoic acid treatment abrogates elastase-induced puimonary emphysema in rats. Nature Med. 3, 675-677 (1997).

2. Cantor, I.O., Shapiro, S.S., di Sant'Agnese, P.A., Cerreta, J.M. \& Trown, P.W. Possible stimulatory effect of retinoic acid on pulmonary macrophages. Experienta 35, 895-896 (1979).

3. Cantor, J.O., Cerreta, J.M., Armand, G. \& Turino G.M. Further investigation of the use of intratracheally administered hyaluronic acid to ameliorate elastase-induced emphysema. Exper. Lung Res. 23, 229-244 (1997).

4. Paiva, S. et al. Assessment of vitamin A status in chronic obstructive pulmonary disease patients and healthy smokers. Am /. Clin. Nutr. 64, 928-934 (1996).

5. Shena, I.P., Kennedy, K.A., Chytil, F. \& Stahlman, M.T. Clinical trial of vitamin A supplementation in infants susceptible to bronchopulmonary dysplasia. 1. Pediatr. 111, 269-277 (1987).

6. Pearson, E., Bose. C. \& Snidow, T. Trial of vitamin A supplementation in very low birth weight infants at risk for bronchopulmonary dysplasia. 1. Pediatr. 121, 420-427 (1992).

7. Cantor, J.O., Cerreta, J.M., Keller, S. \& Turino, G.M. Modulation of airspace enlargement in elastase-induced emphysema by intratracheal instillment of hyaluronidase and hyaluronic acid. Exp. Lung Res. 21, 423-436 (1995).

\section{Erratum}

Changes to the letter from Shibo liang (Nature Med. 3, 367-368; 1997), resulted in some of the references being misnumbered. The correct set of references is available from the author via email (sjiang@nybc.org).
3900 Reservoir Road, N.W. edicine ${ }_{\text {tolal RNA with unparalleled }}$ yield and quality.

- costs less than $\$ 1$ per sample (100 mg tissue or $10^{7}$ cells).

\section{TRI REAGENT ${ }^{\circledR}$} for cells and tissues TRIREAGENT ${ }^{\oplus}$ BD for whole blood and plasma

TRI REAGENT ${ }^{\circledR}$ LS for liquid samples
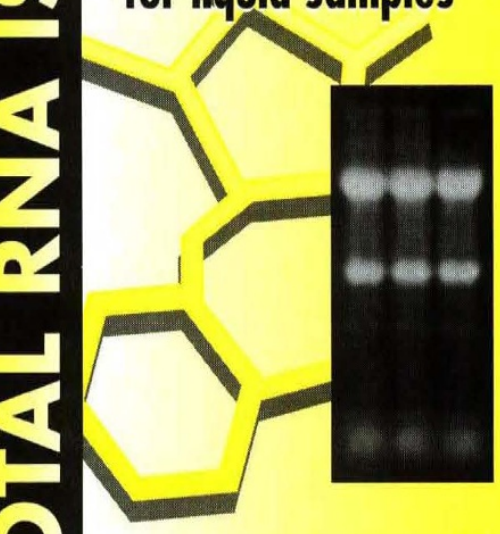

The classic single-step method has been significantly improved to provide higher yields, a shorter protocol, and higher quality RNA from difficult sources! In addition, TRI Reagent has made it possible to isolate simultaneously RNA, DNA and proteins.

(Anal.Biochem.225:163.1995.Biotechniques. 19:942. 1995.)

Isolated RNA is ready for Northern blotting, RT-PCR, and other applications.

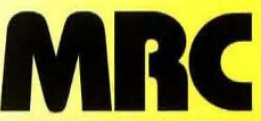
MOLECULAR RESEARCH CENTER, INC. 5645 Montgomery Rd. Cincinnati, OH 45212

Phone: 513-841-0900, 888-841-0900 Fax: $513-841-0080$

E-mail:info@mrcgene.com Visit our website at: http:://www.mrcgene.com

- Australia: 800 - 631-093 • India: 11- 642.5156 - Switzerland: $41-420-9636$ •Itoly: 2-26-40274 - Hong Kong: $275-77569 \bullet$ Austrio: 1-292-3527 - Korea: $2 \cdot 294$ - 6411 • Japon: $3 \cdot 5632 \cdot 9605$ - Fronce: $3 \cdot 88$ - 180722 • Isroel: 8 - 947-2563 - Toiwan: 2-752-3350 - Canada: 905 - 828-2455 - Malaysia: 3-777-2611 • Turkey: 1-212-247-9296 - Germany. 6227-51308, 6172-22073 - Poland: $22 \cdot 635-2455$ - Spain: 1-535-3960 